\title{
Research on Comparative Analysis of Regional Logistics Information Platform Operation Mode Based on Cloud Computing ${ }^{1}$
}

\author{
Changming Li, Xiangdong Zhang and Lijie Li \\ College of Business and Administration, Hebei Normal University of Science \& \\ Technology, Qinhuangdao Hebei Prov.066004, China
}

\begin{abstract}
In order to realize integration of the social logistics resource and provide customized logistics services to the customers, this paper presents a regional logistics platform architecture based on cloud computing through systems analysis. Subsequently, a suggestion about adopting the mode of cooperative operation leading by the enterprise is provided combining the development situation of cloud computing and logistics information public platform in china on the basis of comparative analysis of three kind of operation mode.
\end{abstract}

Key words: Cloud Computing; Logistics Information Platform; Operation Mode

\section{Introduction}

With the development of information technology, Information construction level of logistics enterprises in China has continuously improved. But there are some problems in the process of enterprise logistics information building. Utilizing traditional technology to construct logistics information platform, enterprises need a lot of manpower and material resources to put into. At the same time, it is difficult to realize data sharing between different enterprises because software is independent. In recent years, the logistics information technology based on the Internet of things and the cloud computing has been proposed recently. It provides an effective way to solve the problems of information construction in logistics enterprises. How to apply the cloud computing technology to build a logistics information platform to realize intelligent logistics is one of the main project in the future development of regional logistics information building.

\section{Cloud Computing Technology}

There are still different definition about cloud computing. Definition of cloud computing at Wikipedia has also been updated. At present, the new definition is that Cloud computing is a dynamic and scalable calculation method which provides virtualization resource through the internet. The user does not need to know the internal details of cloud and does not need to have internal expertise about the cloud or directly control infrastructure ${ }^{[1]}$. It can be interpreted it in this way that the cloud can provide you with the information that you need as long as there is a terminal (PC, mobile phone, notebook computer or other equipment) and you can connect to the network When you want to enjoy the services of cloud computing. You do not need to search again and again, also do not need to install the patch.

\footnotetext{
${ }^{1}$ This work was supported by the project of science and technology plan of Science and Technology Department of Hebei Province under Grant Nos. 134576320.
} 


\section{Framework of Regional Logistics Information Platform based on Cloud Computing}

The main function of constructing regional logistics public information platform based on cloud computing is to integrate the independent resources and information distributed in different functional departments of the government and enterprises and to provide a set of standardized information and business services to customers ${ }^{[2]}$. Because logistics industry is operated by adopting non-standard mode in China for a long-term, the existing logistics enterprises which have their own information systems can not switch to cloud computing operation model for one time. The process of constructing regional logistics public information platform will be sequential. Therefore according to the current situation combined with the technology of cloud computing, SaaS and SOA, the construction of regional logistics public information platform can adopt the basic framework of logistics information platform is shown in Figure 1.

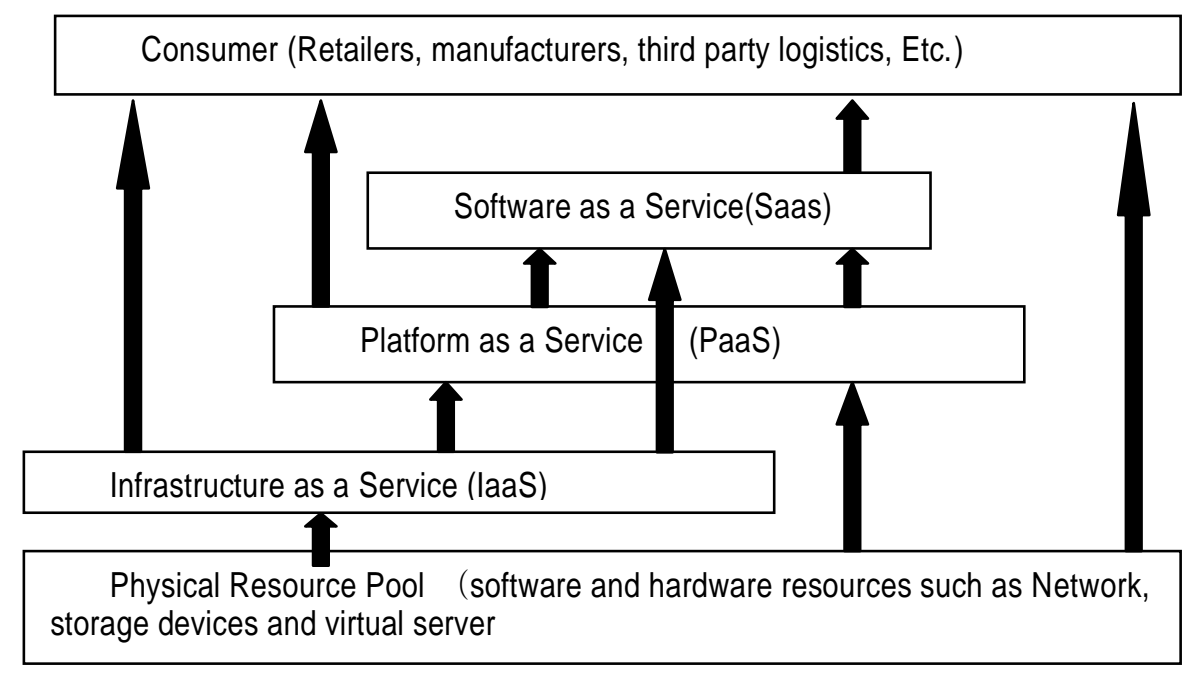

\section{Figure 1. The Basic Framework of Logistics Information Platform based on Cloud Computing}

1) Physical resource pool: The physical resource pool includes hardware resources such as network, storage equipment and virtual server. These distributed resources are connected together through network virtualization in order to compose logistics information platform based on a cloud computing.

2) Infrastructure as a service (IaaS): Application of virtualization technology in physical resources based on cloud computing can achieve full sharing of hardware resources for the customer. Not using a fixed storage space, virtualization technology can allocate resources dynamically according to the actual needs so that it can maximize the user needs with the least resources. The service mode is that provides virtual memory on the network and customers pay rent according to the actual storage capacity, The ability of store and computer memory being formed a virtual pool of resources is provided to customers as measured services ${ }^{[3]}$.In order to improve security and reliability of the whole information platform, the servers within regions are connected into a huge virtual server through introduction of load balance technology and server cluster technology.

3) Platform as a service (PaaS): As the core part of the regional logistics public information platform, the realization of the logistics information collection, calculation, statistics, sharing and other functions is able to complete in this layer ${ }^{[4]}$.In order to ensure the real-time processing, the platform usually adopts distributed calculation and storage technology in the processing of dealing with massive data information. During actual 
deployment of platform design, the calculation function is separated from the business process in order to meet calculation model for the logistics industry needs. The stripped calculation function is packaged into standard services combined with the specific calculation model so that it is convenient to call on by the upper cloud layer. Standardization of industry interface in PaaS provides high performance computing capacity for the industry application ${ }^{[5]}$. Services of development environment and server platform are provided to logistics enterprises at this level. Logistics enterprises can develop their own application program based on the platform and transmit it to other users through the internet.

4) Software as a service (SaaS): Application software is deployed by the platform service providers on the server. The user orders application software service through the network. The service providers collect fees according to time, quantity and other factors of the customized software. On this level, services such as cargo tracking, inventory management, logistics monitoring and intelligent distribution can be provided ${ }^{[6]}$.A variety of application business process is achieved in the cloud application layer and the third party logistics enterprise application services can also be integrated in this layer. Thus evolves into the fourth party logistics information platform. When integrating services of every party in the industry, the platform can share computing ability and storage space for a number of customers paid through the application of the virtual technology. Thereby, the efficiency of utilizing resources is greatly improved and the enterprise operating costs are reduced.While the tenants in sharing resources are isolated from each other to ensure the security of customer data at the same time.

\section{Regional Logistics Platform Architecture based on Cloud Computing}

In order to realize the logistics resource sharing and provide integrated logistics services for customers within regions, the author puts forward regional logistics platform architecture based on cloud computing as shown in Figure 2.

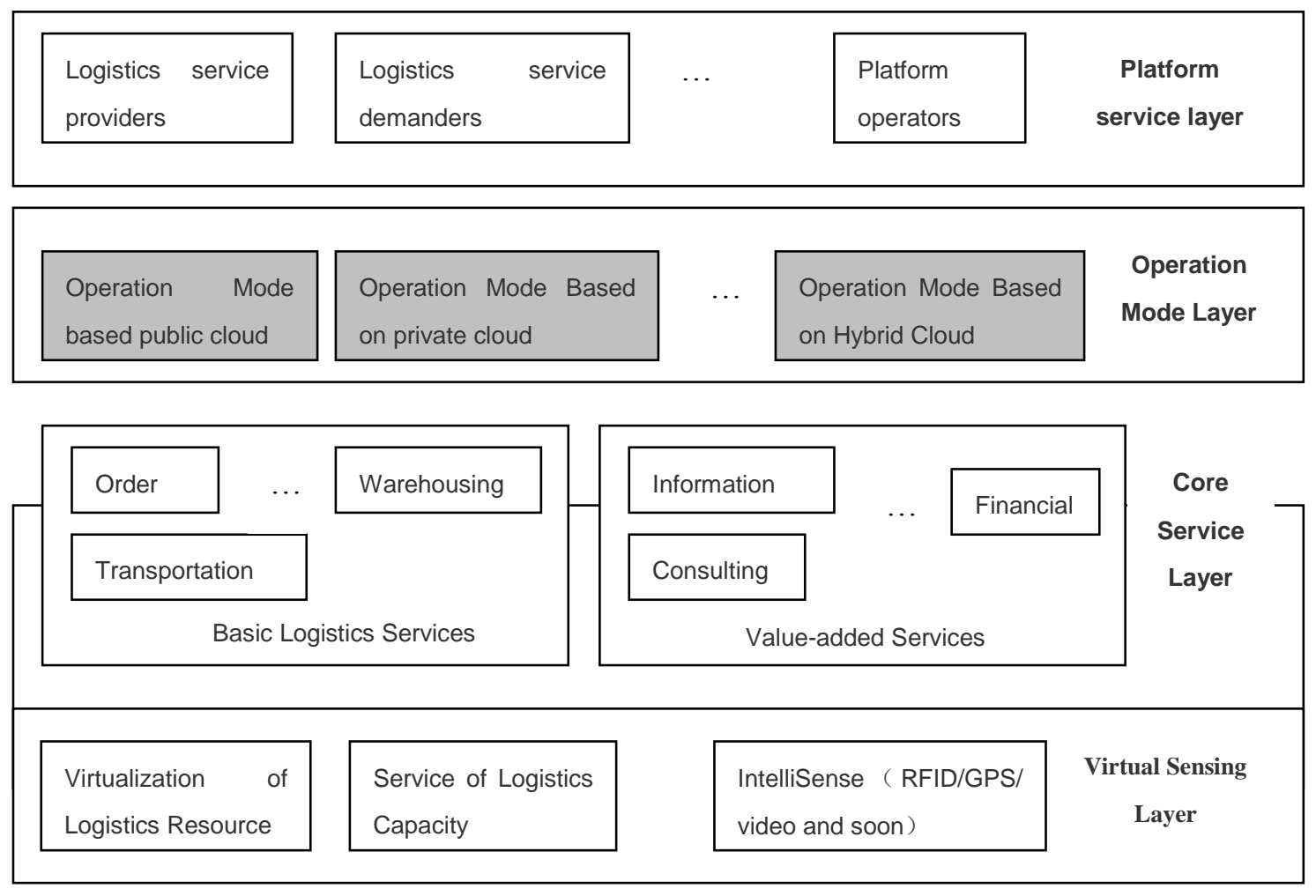

Figure 2. Regional Logistics Platform Architecture based on Cloud 


\section{Computing}

The architecture based on the cloud computing is a hierarchical framework which are divided into 4 levels: Virtual sensing layer, core service layer, application mode layer and platform service layer from the bottom to the top under the support of logistics information platform .

Virtual sensing layer: This layer supports virtualization of logistics resource and service of logistics capacity. Through virtualization and services shielding physical heterogeneity of logistics resources for the purpose of making the logistics resources and services could be interactive and collaborative by the standard interface. At the same time, the layer supports various types of logistics software and hardware resource to access information processing center of logistics platform through RFID, GPS and sensing device. Based on logistics resources perception, recognition, information colleting and processing, this layer realizes the logistics platform intelligent identification and management of the resources.

Core service layer: This layer includes the basic logistics services and value-added services. Basic logistics services relate to order services, transportation services, warehousing services. Logistics value-added services refer to information services, financial services, consulting services and so on.

Operation mode layer: This layer provides different logistics operation mode for the customer and the logistics service provider according to the difference mode of construction and service, including logistics operation mode based public cloud, logistics operation mode based on the private cloud and logistics operation mode based on hybrid cloud.

Platform service layer: This layer provides various modes Including the web portal access, intelligent terminal access, PDA access and system integration interface access to enter logistics platform for participants related logistics. Participants include logistics service providers, logistics service demanders and platform operators. Logistics service providers may be the transportation company, the warehousing company, the third party logistics enterprises, logistics program advisory business, banks and insurance companies. Logistics service demanders are customers that need to be supplied a single logistics service or integrated logistics service. Platform operators can be professional platform operators or telecom operators.

\section{Comparative Analysis and Selection of Regional Logistics Information Platform Operation Mode based on Cloud Computing}

\subsection{Comprehensive Comparison and Analysis of the Operation Mode}

Regional logistics public information platform based on cloud computing is a new modern logistics operation mode. The core is to integrate social logistics resources and innovate logistics operation mode supported by the advanced information technology of cloud computing, Internet of things and advanced management idea of supply chain management $[7,8]$.

In the cloud computing environment, according to the difference mode of construction and service, regional logistics information platform can realize by following 3 modes, i.e., logistics operation mode based on public cloud, logistics operation mode based on the private cloud and logistics operation mode based on hybrid cloud. Applicable scope and the period of three modes is different. Comprehensive comparison and analysis of the various modes are shown in table 1 . Operation mode should be selected according to the policy environment, industry characteristics and application requirements.

Logistics operation mode based on public cloud is an operation mode based on the public logistics services and logistics information platform. Enterprises register and 
publish logistics service in the public cloud logistics platform and customers release logistics service demand in cloud logistics platform. The logistics operation mode based on public cloud can provide function of matching between supply and demand, transaction management, design and optimization of logistics solution, business collaboration, process monitoring, credit management and others. Due to integrating social logistics resources better, the operation mode can provide a variety of high quality logistics services for customers including professional third party logistics and the fourth party logistics service [9]. Because many service providers and customers involved, the operation business mode is more complex. This mode need the government as the subject of investment and operation also relates to business reputation, information security problems. Its mode of operation is still constantly exploring.

Table 1. Comparative Analysis of Various Operation Mode

\begin{tabular}{|c|c|c|c|c|}
\hline No & Operation mode & Advantage & Weaknesses & Scope of Application \\
\hline 1 & $\begin{array}{l}\text { Logistics operation } \\
\text { mode based on } \\
\text { public cloud }\end{array}$ & $\begin{array}{l}\text { Integrating Social logistics } \\
\text { resources, } \\
\text { Providing a variety of logistics } \\
\text { services for customers }\end{array}$ & $\begin{array}{l}\text { Operation of the business mode is } \\
\text { more complex. } \\
\text { Related to business reputation } \\
\text { and information security }\end{array}$ & $\begin{array}{l}\text { The area having good } \\
\text { policy and credit } \\
\text { environment }\end{array}$ \\
\hline 2 & $\begin{array}{l}\text { Logistics operation } \\
\text { mode based on } \\
\text { private cloud }\end{array}$ & $\begin{array}{l}\text { Mode of operation is simple, } \\
\text { driven by the order of } \\
\text { Customer logistics service, } \\
\text { Providing their own } \\
\text { professional logistics services } \\
\text { as the core. }\end{array}$ & $\begin{array}{l}\text { The service offered is relatively } \\
\text { single. } \\
\text { enterprises need to heavily invest } \\
\text { in the project }\end{array}$ & $\begin{array}{l}\text { Applies to the large and } \\
\text { comprehensive logistics } \\
\text { enterprises or the } \\
\text { professional third party } \\
\text { logistics providers which } \\
\text { have certain scale. }\end{array}$ \\
\hline 3 & $\begin{array}{l}\text { Logistics operation } \\
\text { mode based on } \\
\text { hybrid cloud }\end{array}$ & $\begin{array}{l}\text { Have the advantage both } \\
\text { Logistics operation mode based } \\
\text { on public cloud and Logistics } \\
\text { operation mode based on } \\
\text { private cloud }\end{array}$ & $\begin{array}{l}\text { To realize seamless integration } \\
\text { between the logistics platform of } \\
\text { private cloud owned by the core } \\
\text { logistics enterprise and the } \\
\text { logistics platform of public cloud }\end{array}$ & $\begin{array}{l}\text { The area with a good } \\
\text { policy environment and } \\
\text { more mature market }\end{array}$ \\
\hline
\end{tabular}

Logistics operation mode based on private cloud is further deepening and the development based on the information construction of logistics enterprises. Logistics enterprises apply and deploy technology architecture of enterprise information system in accordance with the cloud computing. The logistics enterprise provides logistics resources and ability to carry out the operation and management of information, therefore logistics service mode is different according to the professional logistics enterprises and private cloud [10]. Logistics information platform based on the mode of private cloud is simple. Generally speaking, enterprises with its own professional logistics services as the core are driven by the customer logistics service order, so service quality is controllability strongly. Due to the lack of effective social integration of logistics resources, the service offered is relatively single compared with the logistics operation mode based on public cloud. Because enterprise needs a lot of investment, as a rule, the mode is applicable to the large integrated logistics enterprise or third party professional logistics service providers which have the certain scale.

Logistics operation mode based on hybrid cloud is a composite mode of operation which is composed of the platform of public cloud integrating social logistics resources and the platform of private cloud that logistics enterprises is the core. The logistics enterprises as the leadership provide logistics service solution through the integrated operation mode of supply chain for customers. A hybrid cloud logistics operation mode 
has the advantages of the logistics operation mode based on public cloud and Logistics operation mode based on private cloud. But this mode needs higher requirements to the core logistics enterprises; meanwhile this mode needs realize the seamless integration of public cloud and private cloud.

\subsection{Selection of the Platform Operation Mode}

Construction of the logistics public information platform based on cloud computing and logistics services based on SaaS is the current research focus. Research in china and abroad is still in the exploratory stage. According to the development situation of cloud computing and Internet of things in China at present, it is not realistic to rely on the government as the main body of investment and construction of regional logistics information platform based on cloud computing. While it is very difficult to simply depend on enterprises investment and financing. As a new thing, there is no mature experience for any enterprise, so the operation mode of completely entrust also does not have the application value.

The paper suggests that logistics information platform based on cloud computing should adopt "cooperative operation mode leaded by the enterprise". That is the operation mode of demand oriented, enterprise operation, government guidance and joint planning. The market demand of enterprise is the dominant in this mode and investment planning is drawn up by the government and the enterprise together. Guided by the government, enterprises are responsible for the actual operation in the implementation process. "Cooperative operation mode" combines the advantage of the public cloud and the advantage of private cloud in a body while avoids the disadvantages of them. Implementation roadmap of operation mode leaded by Enterprises is shown in Figure 3.

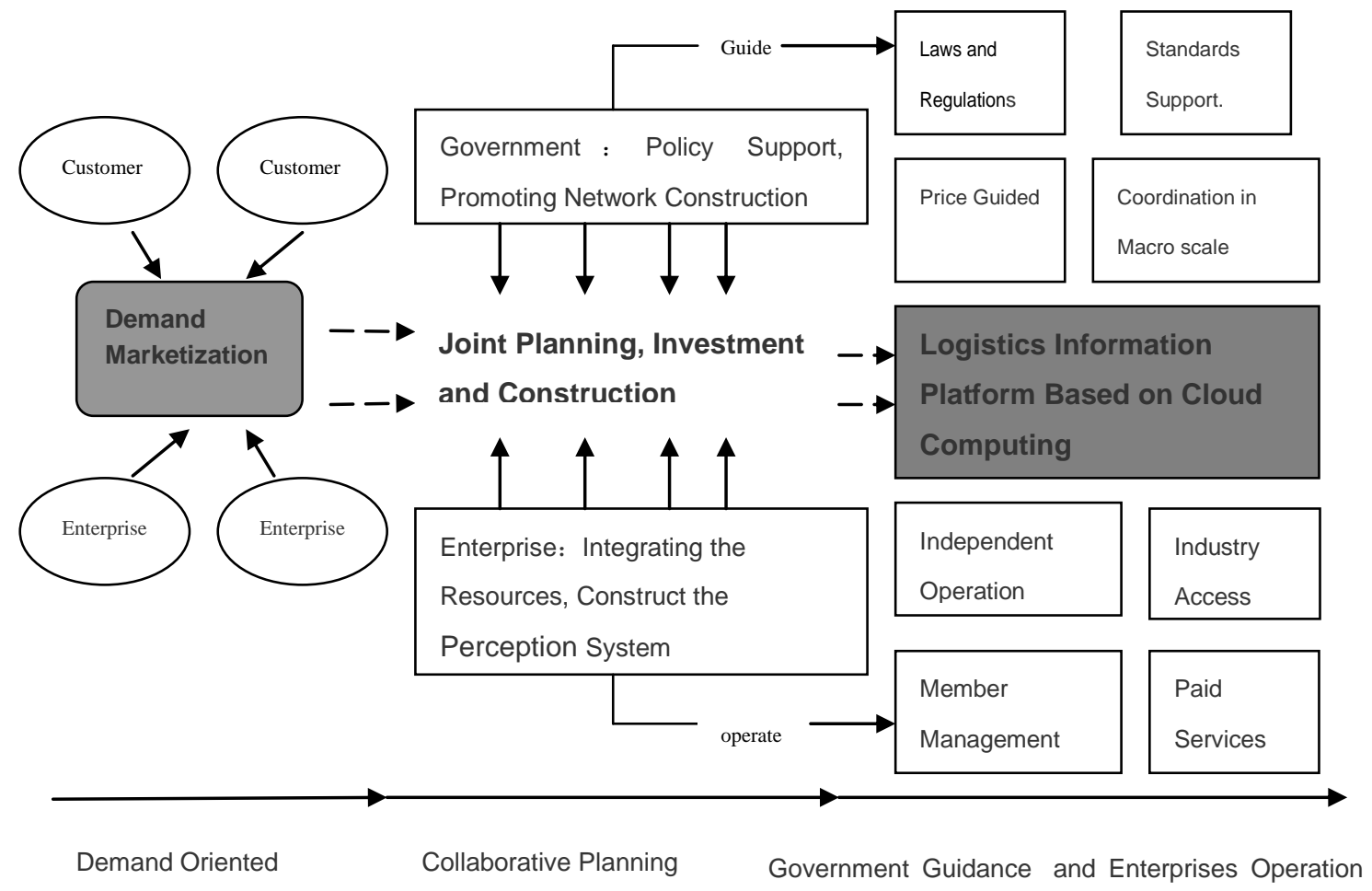

\section{Figure 3. Implementation Roadmap of Cooperative Operation Mode Leaded by Enterprises}

1) Demand oriented and joint planning: Logistics information platform in cloud computing environment will be implemented phased according to the status of funds. 
Cooperative mode with enterprises as the leading should be formed by the market spontaneously at first. The enterprises initiate and gradually integrate the logistics information system resources. Application of cloud logistics service virtualization technology, cloud access technology and logistics service perceptive technology related to enterprises would construct the overall perception system in logistics industry while the government is responsible for the guidance and support. At the same time, the government should undertake integration and construction of infrastructure and logistics security technology in the network layer in order to realize large-scale synchronous data transmission functions to meet the demand of different customer which has various perception of the transmission of information.

2) Government promoting and market operation: The government in charge of the industry sector is responsible for the soft environment which included the relevant policies and regulations, business process, technical standards in the logistics information platform based on cloud computing. At the same time, government gives the guidance for the information service price and comprehensive coordination of the platform management. Logistics enterprises as the main part of the operation platform, should perfect the platform operation mode through introducing the industry access system and membership management in the range of government policies and industry association system allowed. Enterprises can independent operate in the platform such as charging membership dues, service fees, rental fees, advertising fees to the member enterprises who join the information platform. Enterprise oriented collaborative operation mode has a strong feature of market operation, with the nature of the profit obvious. This mode of operation is in accordance with the current development situation of logistics industry in China. The spread of this operation mode is conducive to promoting the application of cloud computing technology in logistics industry in order to maximize the overall value of cloud computing technology in society.

\section{Conclusions}

Logistics public information platform framework is proposed based on the cloud computing technology in this paper. On the basis of system analysis, regional logistics platform architecture based on Cloud Computing is put forward. Through comparative analysis of three kind of operation mode, the paper suggests that the mode of cooperative operation mode leaded by the enterprise should be adopt to construct and operate regional logistics public information platform according to the development situation of cloud computing and Internet of things in China at present.

Logistics public information platform based on cloud computing is an end-to-end collaboration business platform which crosses regional and platform [11]. The platform can realize the sharing of regional logistics resources and optimize the allocation of social logistics resources. It has not only important theoretical value to improve modern logistics function, but also practical applications for the development of modern logistics crossing industry and regional.

\section{References}

[1] S. Li, "Design of Logistics Public Information Platform Based on Cloud Computing Architecture", Value Engineering, vol. 35, no. 31, (2012), pp. 207-208.

[2] J. Yang, "Application of Cloud Computing in Modern Logistics", Logistics Technology, vol. 31, no. 11, (2012), pp. 415-416.

[3] Q. Wang, H. Lv and Y. Jiang, "Study on Cloud Logistics System Framework and Application Mode", Telecommunications Science, vol. 28, no. 3, (2012), pp. 126-132.

[4] X.-H. Li, "Analysis on the Application of Data Mining Based on Cloud Computing", Journal of Changchun University, vol. 22, no. 12, (2012), pp. 1472-1475.

[5] H. Yu, "The Construction of Logistics Information Platform Based on Cloud Computing", Science and Technology Information, vol. 27, no. 1, (2010), pp. 443-444.

[6] X. Weng, "The Research on Building the Regional International Logistics Information Platform", China 
Business and Market, vol. 25, no. 12, (2011), pp. 26-30.

[7] C. Moller, S. Sohail and Chaudhry, "Complex service design: a virtual enterprise architecture for logistics service", Information System Frontier, vol. 10, (2008), pp. 503-518.

[8] C. W. Autry and S. E. Griffis, "Supply chain capital: the impact of structural and relational linkages on firm execution and innovation", Journal of Business Logistics, vol. 29, no. 1, (2008), pp. 26-30.

[9] H. Chen, "Design and Implementation of Logistics Information Platform Based on Cloud Computing", Computer and Modernization, vol. 12, no. 3, (2013), pp. 122-123.

[10] C. Yang and H. Xu, "Design of Logistics Public Information Platform under Cloud Computation", Logistics Technology, vol. 32, no. 5, (2013), pp. 446-448.

[11] C. Liu and F.-Q. Sun, "Security Research On Cloud-based Logistics Service Platform Computer Knowledge and Technology”, vol. 8, no. 9, (2012), pp. 2007-2009.

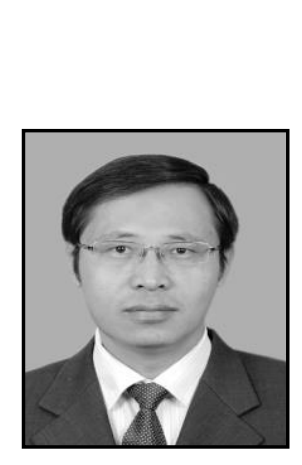

\section{Author}

Changming $\mathbf{L i}$ received the M.S. degree from College of Management and Economics in Business and Administration of Tianjin University. He is a lecturer who engaged in the third party logistics, Procurement management, Supply chain management and other courses teaching and research work in the College of Business and Administration in Hebei Normal University of Science \& Technology. His main research interests are research of in Logistics and supply chain management. He has published papers in the core journals and participated in scientific and teaching research projects. 